\title{
Influence of Biomass Burning on Temporal and Diurnal Variations of Acidic Gases, Particulate Nitrate, and Sulfate in a Tropical Urban Atmosphere
}

\author{
Sailesh N. Behera and Rajasekhar Balasubramanian \\ Department of Civil and Environmental Engineering, National University of Singapore, Singapore 117576 \\ Correspondence should be addressed to Rajasekhar Balasubramanian; ceerbala@nus.edu.sg
}

Received 22 January 2014; Revised 1 April 2014; Accepted 3 April 2014; Published 13 May 2014

Academic Editor: M. Ángeles García

Copyright (C) 2014 S. N. Behera and R. Balasubramanian. This is an open access article distributed under the Creative Commons Attribution License, which permits unrestricted use, distribution, and reproduction in any medium, provided the original work is properly cited.

\begin{abstract}
The present study investigated the temporal and diurnal distributions of atmospheric acidic gases (sulphur dioxide $\left(\mathrm{SO}_{2}\right)$, nitrous acid (HONO), and nitric acid $\left.\left(\mathrm{HNO}_{3}\right)\right)$ and those of particulate nitrate $\left(\mathrm{NO}_{3}{ }^{-}\right)$and sulfate $\left(\mathrm{SO}_{4}{ }^{2-}\right)$ through a comprehensive field campaign during the largest smoke haze episode in Singapore, a representative country in Southeast Asia (SEA). To identify the atmospheric behavior of these pollutants during the smoke haze period, the data generated from the measurement campaign were divided into three distinct periods: prehaze, during haze, and posthaze periods. The $24 \mathrm{hr}$ average data indicated that ambient $\mathrm{SO}_{2}$, $\mathrm{HONO}$, and $\mathrm{HNO}_{3}$ during the smoke haze episodes increased by a factor ranging from 1.2 to 2.6 compared to those during the prehaze and posthaze periods. Similarly, in the case of particulates $\mathrm{SO}_{4}{ }^{2-}$ and $\mathrm{NO}_{3}{ }^{-}$, the factor ranged from 2.3 to 4.2. Backward air trajectories were constructed and used to find the sources of biomass burning to the recurring smoke haze in this region. The air trajectory analysis showed that the smoke haze episodes experienced in Singapore were influenced by transboundary air pollution, caused by severe biomass burning events in the islands of Indonesia.
\end{abstract}

\section{Introduction}

Air pollution due to rapid population growth and urbanization in the region of Southeast Asia (SEA) has been of considerable interest from both scientific and regulatory perspectives due to its impact on global atmospheric chemistry, climate, and human health [1-3]. Among the important air pollutants, fine particulate matter $\left(\mathrm{PM}_{2.5}\right)$ plays a significant role in atmospheric visibility reduction through formation of haze, human health effects, and climate change from the regional to global scale [4-6]. Out of possible sources of $\mathrm{PM}_{2.5}$, atmospheric chemical transformations of precursor gases such as nitrogen oxides $\left(\mathrm{NO}_{x}\right)$, sulfur dioxide $\left(\mathrm{SO}_{2}\right)$, and ammonia $\left(\mathrm{NH}_{3}\right)$ into secondary inorganic aerosol (SIA) through gas-to-particle conversions are not completely understood $[7,8]$. These chemical transformations are strongly influenced by prevailing ambient air temperature, relative humidity, solar radiation, concentrations of precursor gases, and levels of preexisting airborne particulate matter
(PM) $[9,10]$. SIA, represented by ionic species of $\mathrm{SO}_{4}{ }^{2-}$ and $\mathrm{NO}_{3}{ }^{-}$, can account for a significant mass of $\mathrm{PM}_{2.5}$, for example, $31 \%$ in Beijing, China [11], and 33\% in Milan, Italy [12]. The secondary acidic gases such as nitrous acid (HONO), nitric acid $\left(\mathrm{HNO}_{3}\right)$, and sulfuric acid $\left(\mathrm{H}_{2} \mathrm{SO}_{4}\right)$ are produced from natural and manmade emissions of primary gas phase pollutants, $\mathrm{NO}_{x}$ and $\mathrm{SO}_{2}$, through a series of photochemical reactions in the atmosphere [13]. Atmospheric HONO has been studied for a long time, as it is an important source of hydroxyl radicals $(\mathrm{OH})$ in the atmosphere, especially in the morning $[14,15]$.

Biomass burning (BB) in the form of forest and peat fires in Indonesia has a significant impact on the air quality of SEA. The frequent occurrence of forest and peat land fires in Indonesia, caused by land clearing activities, releases large amounts of PM with unique chemical composition into the atmosphere. The resultant particulate emissions undergo transboundary transportation by prevailing winds and are transformed into regional smoke haze episodes 
affecting several neighboring countries in SEA, most notably, Singapore, Malaysia, Indonesia, and Thailand. The frequent occurrence of BB in SEA and the transport of the resultant smoke haze containing a high concentration of $\mathrm{PM}_{2.5}$ have been of great concern because of a high population density and the presence of sensitive ecosystems in the region $[16,17]$.

El Niño is a phenomenon, characterized by prolonged warm periods that occur in the Pacific Ocean around the equator, and results in weather changes all over the world $[18,19]$. For example, the El Niño/Southern Oscillation (ENSO) phenomenon significantly reduced the amount of rainfall and prolonged dry spells in SEA, resulting in longer duration of drought during 1997-1998 [19, 20]. The drought increased the susceptibility of some forests and rangelands to fires and in conjunction with slash-and-burn methods of land clearance could trigger uncontrolled forest fires [19]. In addition, during the drought period caused by ENSO in August 1997, the biomass fires, started deliberately by oilpalm and timber-plantation firms for land-clearing, caused the second largest forest fire disaster in Indonesia [20, 21].

The smoke haze episode occurred in August 1997 for several months, in which more than 1,500 biomass fires consumed more than 300,000 hectares mainly in the Kalimantan and Sumatra islands $[16,21]$. As a result, large amounts of gaseous and particulate pollutants were emitted into the atmosphere, which affected the environmental quality of neighboring countries (e.g., Singapore, Malaysia, and Thailand) and the Indonesian Islands for several months [21]. In view of the extensive potential impacts of $\mathrm{BB}$, a number of studies were carried out to characterize the resultant particulate pollutants in different parts of SEA such as Brunei Darussalam [22, 23], Malaysia [24, 25], and Singapore [16, $17,26,27]$. However, these studies did not fully address the atmospheric behavior of acidic precursor gases $\left(\mathrm{SO}_{2}, \mathrm{HONO}\right.$, and $\mathrm{HNO}_{3}$ ) and the formation of $\mathrm{SO}_{4}{ }^{2-}$ and $\mathrm{NO}_{3}{ }^{-}$in $\mathrm{PM}_{2.5}$ during the largest haze episode.

Recent studies in China revealed that SIA made a major contribution to the PM composition during smoke haze events and provided insights into the chemical conversion of primary air pollutants to SIA (e.g., $[28,29]$ ). Similar information on the atmospheric chemistry responsible for formation of SIA in SEA during both haze and nonhaze periods is required for chemical transport model development and validation. To close this knowledge gap and to provide insights into the chemistry behind the formation of SIA from BB emissions, we analyzed the datasets collected from the 1997-1998 smoke haze episode in view of its high intensity, long duration, and significant impact on regional air quality in SEA.

Specifically, this work investigated the chemical characterization of acidic gases and studied the formation of particulates nitrate and sulfate through a comprehensive field campaign during the largest haze episode in Singapore, a representative country in SEA. In this study, we used the annular denuder system (ADS) as an effective air sampler to collect acidic gases and fine particles in the ambient air from June 1997 to February 1998. The specific objectives of the study were as follows: (1) simultaneous measurements of acidic gases $\left(\mathrm{SO}_{2}, \mathrm{HONO}\right.$, and $\left.\mathrm{HNO}_{3}\right)$ and the corresponding water-soluble acidic components of $\mathrm{PM}_{2.5}\left(\mathrm{NO}_{3}{ }^{-}\right.$and $\left.\mathrm{SO}_{4}{ }^{2-}\right)$; (2) investigation of their temporal as well as diurnal trends during haze and nonhaze periods; (3) formation of particulates $\mathrm{NO}_{3}{ }^{-}$and $\mathrm{SO}_{4}{ }^{2-}$ during haze and nonhaze periods along with their relationships with the prevailing meteorology; and (4) examination of the origin of air masses received at the receptor during the sampling period.

\section{Materials and Methods}

2.1. Sampling Site Location. Air sampling was carried out at the Atmospheric Research Station located on the roof of one of the tallest buildings at the campus of National University of Singapore (latitude $1^{\circ} 18^{\prime} \mathrm{N}$ and longitude $103^{\circ} 46^{\prime} \mathrm{E}$ ) from 10 June 1997 to 9 February 1998. The air sampling was done in an interval of $24 \mathrm{hr}$ on a daily basis on most of the days during the sampling period. Out of the 244 days of air sampling, daytime (8:00 AM to 8:00 PM) and nighttime (8:00 PM to 8:00 AM) sampling were done on a 12-hour basis for 31 days (11 days for haze period and 20 days for nonhaze period), from 24 July 1997 to 03 October 1997. To assess the diurnal patterns of the air pollutants, air sampling was done in an interval of $4 \mathrm{hr}$ 7:00 AM to 7:00 AM for four days (2 days for hazy and 2 days for nonhazy days) during the sampling period. The site is approximately $1.0 \mathrm{~km}$ away from the open sea. The air quality at the measurement site in the absence of regional smoke haze episodes is mainly influenced by local emissions from chemical industries, major power plants, and petroleum refineries located in the southwest direction and also by urban vehicular traffic [17]. Important sources of air pollution in Singapore can be classified into burning of fossil fuel for heat generation in industries, electricity generation, transportation, and burning of fuel for domestic cooking. Transboundary air pollution has a major influence on the local air quality of Singapore, especially during the occurrence of $\mathrm{BB}$ episodes in Indonesia $[16,17]$. A severe smoke haze episode was experienced in Singapore from August to October 1997 due to uncontrolled forest and peat fires in Indonesia followed by another haze episode in early 1998. The biomass fires (hot spots) in Indonesia took place in an approximate radius of $300 \mathrm{~km}$ to $1000 \mathrm{~km}$ from Singapore.

2.2. Sampling Method. The ADS sampling unit from University Research Glassware, USA, was employed in this study, which consisted of a Teflon-coated aluminium cyclone, three annular denuder tubes in series, and a two-stage filter assembly. The Teflon-coated aluminium cyclone was designed to allow entry of particles $<2.5 \mu \mathrm{m}$ at an airflow rate of $10 \mathrm{~L} / \mathrm{min}$. The denuder tube was $242 \mathrm{~mm}$ long and had three concentric channels with the annular width of $1.0 \mathrm{~mm}$. The concentric tubes were frosted to increase the surface area available for coating, and as a result, the capacity of the denuder was increased. The inner glass tubes are inset $25 \mathrm{~mm}$ from one end of the outer Teflon-coated stainless steel tube to serve as the flow-straightened end. The denuders were assembled in such a way that the flow-straightened end always followed the flush end of the previous denuder to allow the laminar 
flow conditions to be restored. Three denuders were used in series to eliminate chemical interference during the course of air sampling. The first denuder, coated by sodium chloride $(\mathrm{NaCl})$ methanol water solution, collected gaseous $\mathrm{HNO}_{3}$ with an efficiency of about $97 \%$. The other two identical denuders, both coated with sodium carbonate $\left(\mathrm{NaCO}_{3}\right)$ glycerol-methanol solution, were used for the collection of HONO in order to exclude artifacts from collection of nitrogen dioxide and other potential nitrogen compounds, such as peroxyacetyl nitrate. $\mathrm{SO}_{2}$ was collected mostly on the second denuder with a small part on the first denuder.

The denuder tube assembly was followed by a two-stage filter pack. The filter pack consisted of a Teflon filter with $47 \mathrm{~mm}$ diameter and $1 \mu \mathrm{m}$ porous size for collection of fine particles, followed by a nylon filter with $47 \mathrm{~mm}$ diameter and $1 \mu \mathrm{m}$ porous size for the collection of nitric acid formed from the dissociation of ammonium nitrate $\left(\mathrm{NH}_{4} \mathrm{NO}_{3}\right)$ particles originally on the Teflon filter. Filters were supported by a stainless steel screen and separated by a Teflon spacer. The ADS sampler, together with the cyclone and filter pack, was installed vertically in an insulated sampling box during the sampling process. Temperature in the sampling box was maintained at $2^{\circ} \mathrm{C}$ above the ambient atmosphere to prevent condensation. From the analytical results, it was observed that $\mathrm{NO}_{3}{ }^{-}$present in nylon filters were $41.0 \%$ and $32.7 \%$ of total $\mathrm{NO}_{3}{ }^{-}$during daytime and nighttime, respectively. It should be noted that the values reported in this study represent the sum of results from both Teflon and nylon filters.

Chemically coated denuders were dried following the coating with purified nitrogen using the drying train (URG2000-30I) and manifold (URG-2000-30H) in the laboratory before being subjected to air sampling. The denuders exposed to the ambient air were extracted using $10 \mathrm{~mL}$ ultrapure Milli-Q water immediately after sampling, and the aliquots were refrigerated till the chemical analysis, which was undertaken within a week after air sampling. During the measurement period, meteorological parameters (temperature, relative humidity, wind speed, wind direction, and rainfall) were recorded using the Solus meteorological system (Texas Electronics) installed on the roof of the research station with a time resolution of $1 \mathrm{hr}$.

2.3. Chemical Analysis. The exposed denuders and filter samples were used for chemical analysis of water-soluble ionic species. Filters were equilibrated in a controlled dry box with temperature of $20 \pm 5^{\circ} \mathrm{C}$ and relative humidity of $30 \pm 2 \%$ for at least $24 \mathrm{hr}$ before and after the sampling. Field blanks (one in ten filters) were collected and analyzed in parallel to the exposed filter papers as a part of QA/QC. After sampling, the filters were transferred to individual filter containers and stored at $4^{\circ} \mathrm{C}$ until extraction and subsequent chemical analysis. The nylon filter was extracted using $10 \mathrm{~mL} 1.8 \mathrm{mM} \mathrm{Na}_{2} \mathrm{CO}_{3} / 1.7 \mathrm{mM} \mathrm{NaHCO}_{3}$ solution (anion ion chromatograph eluent) to recover collected $\mathrm{HNO}_{3}$ volatilized from the Teflon filter. The Teflon filter was extracted by using $0.5 \mathrm{~mL}$ iso-propanol and $10 \mathrm{~mL}$ ultrapure Milli-Q water. The samples extracted from Teflon and nylon filters were ultrasonicated at a temperature of about $30^{\circ} \mathrm{C}$ for $1 \mathrm{hr}$ and were filtered through a $0.22 \mu \mathrm{m}$ filter paper to remove insoluble matter.

Chemical analyses of the extracted samples from denuders, Teflon filters, and nylon filters were carried out using High Performance Liquid Chromatography, Perkin Elmer series 200 HPLC system together with the Altech 550 Conductivity Detector, and Altech 335 Solid Phase Chemical Suppressor. All QA/QC procedures for chemical analyses were maintained as per the standard method. The procedures for quantification of acidic gases from the results of denuder samples were followed as per the method by William et al. [30]. The first denuder stage collected all sampled $\mathrm{HNO}_{3}$ as $\mathrm{NO}_{3}{ }^{-}$, as the diffusivity of $\mathrm{HNO}_{3}$ was high and diffusion to the sidewall was quick. It was assumed that the second denuder stage collected all sampled $\mathrm{HONO}$ as nitrite $\left(\mathrm{NO}_{2}{ }^{-}\right)$, which can be oxidized to $\mathrm{NO}_{3}{ }^{-}$. The first and second denuder stages together collected all $\mathrm{SO}_{2}$ as sulfite $\left(\mathrm{SO}_{3}{ }^{2-}\right)$, which was completely oxidized to $\mathrm{SO}_{4}{ }^{2-}$. It should be noted that $50 \mu \mathrm{L}$ of $30 \% \mathrm{H}_{2} \mathrm{O}_{2}$ was added to the sample solutions to oxidize the $\mathrm{SO}_{3}{ }^{2-}$ to $\mathrm{SO}_{4}{ }^{2-}$ completely and samples were allowed to stand for $30 \mathrm{~min}$ prior to the chromatography analysis. The amounts of $\mathrm{NO}_{2}{ }^{-}$and $\mathrm{NO}_{3}{ }^{-}$collected on the third denuder represent the amounts of interfering gases such as $\mathrm{NO}_{2}$ collected on the second denuder.

The method detection limits (MDLs) for all ions were determined by using the results from 10 repeated analyses of the deionized water and were calculated as three times the standard deviation of the deionized water. MDLs for $\mathrm{NO}_{2}{ }^{-}, \mathrm{NO}_{3}{ }^{-}$, and $\mathrm{SO}_{4}{ }^{2-}$ were found as $4.2 \mu \mathrm{g} \mathrm{L}^{-1}, 5.0 \mu \mathrm{g} \mathrm{L}^{-1}$, and $3.4 \mu \mathrm{g} \mathrm{L}^{-1}$, respectively. Ion recovery efficiencies were determined by spiking a known quantity of ion mass, and reproducibility tests were performed by replicate analysis, one out of every 10 samples. The results showed that recovery efficiencies varied between $95 \%$ and $105 \%$, and the reproducibility tests had acceptable results within $\pm 10 \%$ for all species analyzed. In this study, blank samples from each denuder coating process were collected and these samples were subjected to chromatography analysis. Similarly nylon and Teflon filter blank samples were also analyzed. The values reported in this study are results obtained after subtracting the blank values from the experimental values. As the sampling site was located near to the sea surface, we estimated aerosol components which are free from the sea salt influence. The concentrations of non-sea-salt $\mathrm{SO}_{4}{ }^{2-}$ were estimated by using the empirical formula given by Kennish [31] and the concentrations reported in this paper are from non-sea-salt components.

\section{Results and Discussion}

3.1. Overall Results. Table 1 provides a statistical summary of the measured $24 \mathrm{hr}$ mean concentrations of air pollutants and the corresponding meteorological parameters. The ratios of the highest concentration observed to the lowest concentration were $31.5,9.0,70.2,95.8$, and 33.1 for $\mathrm{SO}_{2}$, $\mathrm{HONO}, \mathrm{HNO}_{3}, \mathrm{NO}_{3}{ }^{-}$, and $\mathrm{SO}_{4}{ }^{2-}$, respectively. Such higher variations among the pollutants imply the complexity of 
TABLE 1: Statistical summary of air quality (unit: $\mu \mathrm{g} \mathrm{m}^{-3}$ ), meteorology, and PSI on a $24 \mathrm{hr}$ basis.

\begin{tabular}{|c|c|c|c|c|c|}
\hline Species & $N$ & Mean & S.D. & Min & Max \\
\hline $\mathrm{SO}_{2}$ & 239 & 17.9 & 10.8 & 1.7 & 54.9 \\
\hline HONO & 239 & 3.1 & 1.8 & 0.9 & 8.2 \\
\hline $\mathrm{HNO}_{3}$ & 239 & 0.6 & 0.5 & 0.1 & 3.5 \\
\hline $\mathrm{SO}_{4}{ }^{2-*}$ & 239 & 5.3 & 4.7 & 1.1 & 34.8 \\
\hline $\mathrm{NO}_{3}^{-}$ & 239 & 1.0 & 1.2 & 0.1 & 9.6 \\
\hline$T\left({ }^{\circ} \mathrm{C}\right)$ & 239 & 27.2 & 1.1 & 24.5 & 29.6 \\
\hline $\mathrm{RH}(\%)$ & 239 & 81.2 & 5.8 & 73.3 & 97.8 \\
\hline WS $\left(\mathrm{m} \mathrm{s}^{-1}\right)$ & 239 & 2.8 & 1.1 & 0.6 & 5.3 \\
\hline $\mathrm{WD}\left({ }^{\circ}\right)$ & 239 & 162.7 & 46.6 & 64.7 & 316.3 \\
\hline PSI & 239 & 55 & 18 & 18 & 139 \\
\hline
\end{tabular}

* The concentrations are reported for non-sea-salt particles; $N$ : number of valid 24 hr observations; S.D.: standard deviation; Min: minimum; Max: maximum; $T$ : temperature; RH: relative humidity; WS: wind speed; WD: wind direction; PSI: Pollutant Standards Index.

the atmospheric chemical reactions that depend on many factors including their origins and chemical and/or physical behaviors in the atmosphere under different meteorological conditions. The influence of the El Nino phenomenon and the resultant smoke haze experienced between August and November 1997 in SEA is discussed in a subsequent section.

Compared to $\mathrm{SO}_{2}$ and $\mathrm{H}_{2} \mathrm{SO}_{4}$, the atmospheric chemistry of $\mathrm{HNO}_{3}$ and $\mathrm{HONO}$ has not been widely studied because of the difficulty involved in their air sampling. $\mathrm{HNO}_{3}$ and HONO together with their precursors, nitric oxide (NO), nitrogen dioxide $\left(\mathrm{NO}_{2}\right)$, nitrate radical $\left(\mathrm{NO}_{3}\right)$, and nitrogen pentoxide $\left(\mathrm{N}_{2} \mathrm{O}_{5}\right)$, are important trace constituents of the troposphere that have a wide range of atmospheric effects. For example, it has been reported by Shaw Jr. et al. [32] and Hering et al. [33] that $\mathrm{NO}_{x}$ is essential for the photochemical production of tropospheric ozone, which is considered as one of the main secondary air pollutants in polluted air masses. Both $\mathrm{HNO}_{3}$ and $\mathrm{HONO}$ represent the oxidized products of $\mathrm{NO}_{x}$ through a series of photochemical reactions in the atmosphere. They have high vapor pressure and therefore exist mainly in the gaseous phase. However, $\mathrm{HNO}_{3}$ and $\mathrm{HONO}$ are quite different in their formations, transformation, and removal mechanism in the atmosphere $[34,35]$.

Pollutant Standards Index (PSI) is an index developed by the United States Environmental Protection Agency (USEPA) which indicates the prevailing status of ambient air quality in terms of good (0 to 49), moderate (50 to 99), and unhealthy (>100) for the general public (http://app2.nea.gov.sg/index.aspx). The PSI is estimated from the levels of criteria air pollutants through two stages: (i) individual subindex for each of the six categories, namely, $24 \mathrm{hr} \mathrm{PM}_{10}$ (particles with diameter less than $10 \mu \mathrm{m}$ ), $24 \mathrm{hr}$ $\mathrm{SO}_{2}, \mathrm{TSP} \times \mathrm{SO}_{2}, 8 \mathrm{hr} \mathrm{CO}, 1 \mathrm{hr} \mathrm{O}$, and $1 \mathrm{hr} \mathrm{NO}_{2}$, is calculated, and (ii) once the subindex is obtained for each pollutant, the maximum of all the subindices is considered as the overall PSI for the day. The smoke haze episode experienced in SEA between August and November 1997 made a substantial contribution to the average concentration of all the pollutants collected during the sampling period. It was found that all the air pollutants listed in Table 1 had higher concentrations during the smoke haze (months August through November) than those collected before and after the haze. More information about the air quality during haze and nonhaze periods is provided in a subsequent section.

The results obtained from this study on levels of $\mathrm{HNO}_{3}$, $\mathrm{NO}_{3}{ }^{-}$, and $\mathrm{SO}_{4}{ }^{2-}$ are comparable to those from other studies of the world, for example, Nara, Japan [36], and Bangkok, Thailand [37]. However, in comparison to the previous studies accomplished in Western Europe and the United States, it can be seen that HONO concentrations collected in Singapore were somewhat higher than those observed in the Europe area, for example, Sjodin and Ferm [38] in Sweden as $0.1-1.3 \mu \mathrm{g} \mathrm{m}^{-3}$ and Allegrini et al. [39] in Italy as $0.4-$ $1.7 \mu \mathrm{g} \mathrm{m}^{-3}$.

High temperature and moisture contents are the typical climatic features of the tropical region which could make a positive influence on the production and transportation of the nitrogen family including $\mathrm{NH}_{3}, \mathrm{NO}_{x}, \mathrm{~N}_{2} \mathrm{O}$, and $\mathrm{NH}_{4}{ }^{+}$. Although we do not have data for these species in the gas phase during the sampling, comparatively high concentrations of $\mathrm{NH}_{4}^{+}$in the rain water have been observed in the same site [16]. Additionally, observations of similar increases in the soil system were reported by Wetselaar [40]. Increase in the concentration of these nitrogen-containing components could lead to an increase of $\mathrm{NO}$ and $\mathrm{NO}_{2}$ which are the main precursors of $\mathrm{HONO}$ in the atmosphere.

Although it is difficult to get the sufficient precise quantification of the production of $\mathrm{NO}_{x}$ from the lightning, earlier studies showed that it is potentially the largest natural source and its magnitude may be equivalent to that of man-made emissions [41]. As thunderstorm occurs quite frequently in this region, it might have a significant contribution to the atmospheric concentration of $\mathrm{NO}_{x}$ and therefore the secondary pollutant HONO. Due to the location of the sampling site near to the highway, it was likely to be impacted by the vehicular traffic. Earlier study by Perner et al. [42] had also reported the primary emissions of $\mathrm{HONO}$ in motor vehicles. In addition, more $\mathrm{HNO}_{3}$ and $\mathrm{HONO}$ can be produced from 
their precursors $\mathrm{NO}_{x}$, as traffic is one of the main sources of anthropogenic sources of $\mathrm{NO}_{x}$ in the atmosphere.

On the other hand, the relatively high rainfall intensity in this region cannot lead to a significant removal of HONO in the atmosphere due to its extremely low water solubility. Resulting from the high formation and low removal rate, the HONO concentration measured was relatively higher than most data collected in Europe. It should be noted that former studies conducted by the European and American researchers have revealed that in most cases HONO had higher concentrations than $\mathrm{HNO}_{3}$. Sjodin and Ferm [38] even reported that high concentrations of HONO were only observed in the highly polluted area such as Los Angeles.

3.2. Levels during Haze and Nonhaze Episodes. To elucidate the influence of the smoke haze, caused by BB, on the ambient air quality, we have classified the measurement periods into three groups: (i) prehaze episode (10 June 1997 to 22 August 1997), (ii) haze episode (23 August 1997 to 12 November 1997), and (iii) posthaze episode (14 November 1997 to 9 February 1998). In this section, we discuss the effects of smoke haze on the air quality on a basis of 24-hour observations.

Figure 1 shows the time-series plots of daily concentrations of pollutants along with PSI values during prehaze, haze, and posthaze episodes. In comparison to PSI, $\mathrm{SO}_{2}$ did not show a proportionate increase during the haze period. This indicates that higher PSI during the haze period can be attributed to more dominant contributions of $\mathrm{PM}_{10}$ over other criteria pollutants. The slight increase in $\mathrm{SO}_{2}$ levels during the haze period may be due to the phenomena of temperature inversion that resulted in reduced vertical mixing of $\mathrm{SO}_{2}$ and reduced visibility for a favorable conversion of $\mathrm{SO}_{2}$ into $\left(\mathrm{NH}_{4}\right)_{2} \mathrm{SO}_{4}$. An earlier study by Kaiser and Qian [43] had reported that the atmospheric aerosol loading during haze episodes decreased the duration and intensity of sunshine in the region of southeastern China. Therefore, it could be inferred that the levels of $\mathrm{SO}_{2}$ measured during the sampling period were probably due to the local emission effects. In addition, several studies in the past have reported that $\mathrm{SO}_{2}$ is converted into $\mathrm{SO}_{4}{ }^{2-}$ particles in the few hours of its emission, perhaps through in-cloud oxidation by $\mathrm{H}_{2} \mathrm{O}_{2}$, and $\mathrm{SO}_{4}{ }^{2-}$ particles are stable compounds with lower vapor pressure [44]. As a result, once $\mathrm{SO}_{4}{ }^{2-}$ particles are formed in the atmosphere, there is no possibility for the final products to get back to the original reactants through reversible reaction. However, in the case of $\mathrm{NO}_{3}{ }^{-}$particles, these particles are semivolatile in nature and can undergo reversible reactions under favorable thermodynamics. Hence, it is difficult to identify the sources of its precursors from local or long-range transportation. In this study, the levels of $\mathrm{HONO}, \mathrm{HNO}_{3}$, $\mathrm{NO}_{3}{ }^{-}$, and $\mathrm{SO}_{4}{ }^{2-}$ showed a significant increase during the haze period in comparison to those during prehaze and posthaze periods. The reason might be due to long-range transport of pollutants from $\mathrm{BB}$ in the neighboring countries. This possibility for the influence of $\mathrm{BB}$ over the levels of these pollutants is examined in a subsequent section.

Figure 2 shows overall results of $24 \mathrm{hr}$ average values of pollutants along with PSI in three different episodes. The
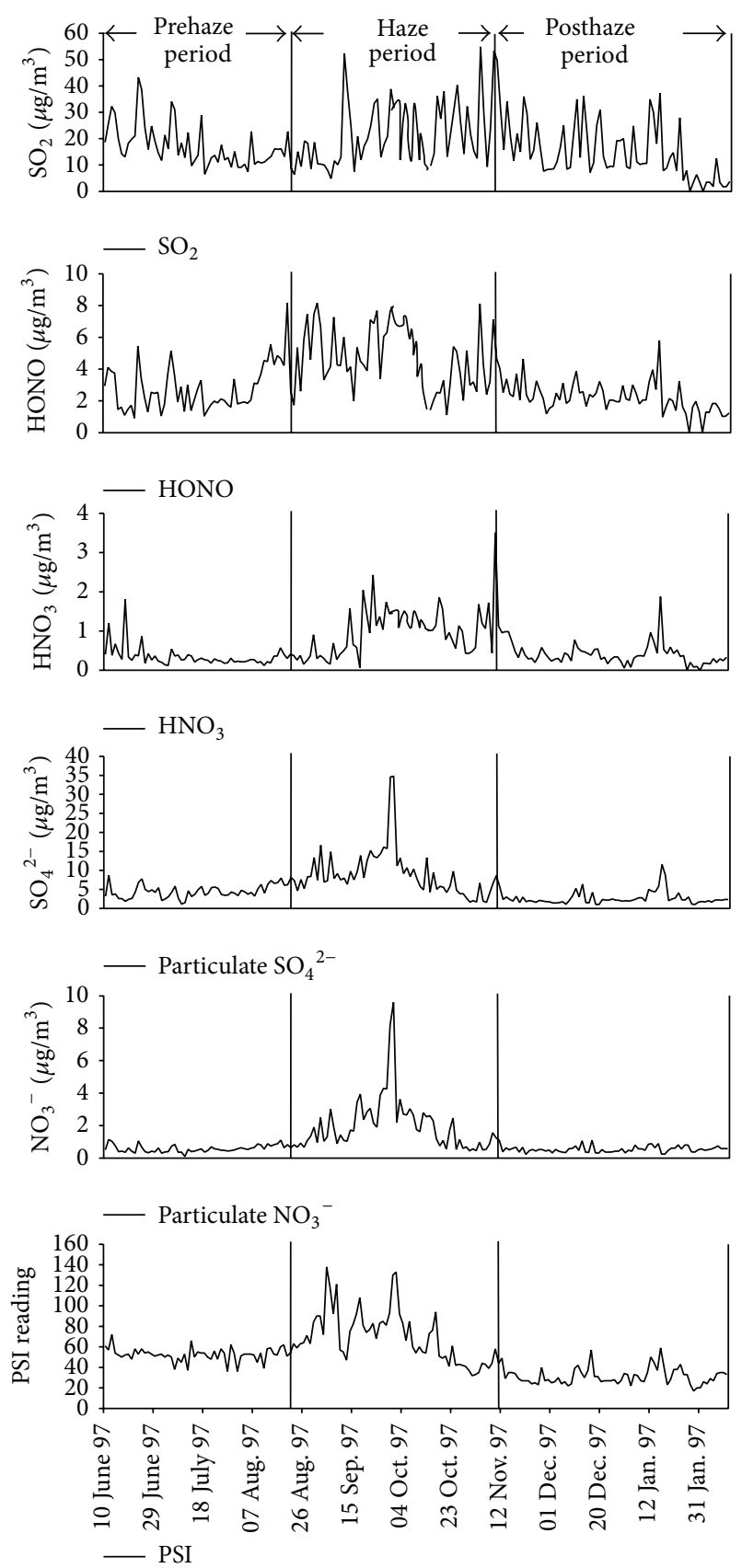

FIGURE 1: Time-series plots of daily concentrations of air pollutants along with PSI values during prehaze, haze, and posthaze periods.

following observations were made during these periods: (i) $\mathrm{SO}_{2}$ level during haze period was 1.22 and 1.18 times of prehaze and posthaze episodes, respectively, (ii) HONO level during haze period was 1.73 and 1.87 times of prehaze and posthaze episodes, respectively, (iii) $\mathrm{HNO}_{3}$ level during the haze period was 2.57 and 1.67 times of prehaze and posthaze episodes, respectively, (iv) $\mathrm{SO}_{4}{ }^{2-}$ level during the haze period was 2.32 and 3.72 times of prehaze and posthaze episodes, respectively, (v) $\mathrm{NO}_{3}{ }^{-}$level during the haze period was 4.12 and 4.19 times of prehaze and posthaze episodes, respectively, and (vi) PSI levels during haze period were 1.48 and 2.39 times 
TABLE 2: Daytime and nighttime levels of air pollutants (unit: $\mu \mathrm{g} \mathrm{m}^{-3}$ ) and meteorological parameters based on $12 \mathrm{hr}$ average.

\begin{tabular}{|c|c|c|c|c|c|c|c|c|c|c|}
\hline \multirow{3}{*}{ Parameters } & \multicolumn{5}{|c|}{ Haze period $^{\mathrm{a}}$} & \multicolumn{5}{|c|}{ Nonhaze period $^{\mathrm{b}}$} \\
\hline & \multicolumn{2}{|c|}{ Daytime $^{c}$} & \multicolumn{2}{|c|}{ Nighttime $^{c}$} & \multirow{2}{*}{$\mathrm{D} / \mathrm{N}^{\mathrm{d}}$} & \multicolumn{2}{|c|}{ Daytime $^{c}$} & \multicolumn{2}{|c|}{ Nighttime $^{c}$} & \multirow{2}{*}{$\mathrm{D} / \mathrm{N}^{\mathrm{d}}$} \\
\hline & Mean & $\mathrm{SD}$ & Mean & $\mathrm{SD}$ & & Mean & $\mathrm{SD}$ & Mean & $\mathrm{SD}$ & \\
\hline $\mathrm{SO}_{2}$ & 10.5 & 3.4 & 13.0 & 8.7 & 0.8 & 11.1 & 3.7 & 13.9 & 7.5 & 0.8 \\
\hline HONO & 5.6 & 1.9 & 5.7 & 2.0 & 1.0 & 2.8 & 1.3 & 4.4 & 2.7 & $0.6^{\mathrm{e}}$ \\
\hline $\mathrm{HNO}_{3}$ & 0.6 & 0.5 & 0.2 & 0.1 & $3.0^{\mathrm{e}}$ & 0.4 & 0.2 & 0.2 & 0.1 & $2.0^{\mathrm{e}}$ \\
\hline $\mathrm{SO}_{4}{ }^{2-}$ & 10.5 & 4.2 & 8.9 & 3.6 & 1.2 & 5.9 & 2.1 & 5.2 & 1.5 & 1.1 \\
\hline $\mathrm{NO}_{3}^{-}$ & 1.6 & 0.8 & 1.4 & 0.9 & 1.1 & 0.8 & 0.2 & 0.7 & 0.2 & 1.1 \\
\hline$T\left({ }^{\circ} \mathrm{C}\right)$ & 29.3 & 1.9 & 25.3 & 0.4 & $1.2^{\mathrm{e}}$ & 29.7 & 1.7 & 25.7 & 0.5 & $1.2^{\mathrm{e}}$ \\
\hline $\mathrm{RH}(\%)$ & 75.0 & 6.2 & 86.6 & 5.3 & 0.9 & 75.3 & 6.4 & 86.9 & 5.5 & $0.9^{\mathrm{e}}$ \\
\hline WS $\left(\mathrm{m} \mathrm{s}^{-1}\right)$ & 3.9 & 0.9 & 2.9 & 0.5 & $1.3^{\mathrm{e}}$ & 4.7 & 0.7 & 3.2 & 0.7 & $1.5^{\mathrm{e}}$ \\
\hline $\mathrm{WD}\left({ }^{\circ}\right)$ & 155.2 & 34.4 & 135.7 & 21.1 & 1.1 & 165.2 & 21.8 & 143.4 & 17.8 & $1.2^{\mathrm{e}}$ \\
\hline
\end{tabular}

${ }^{a}$ Haze period from 23 August 1997 through 03 October 1997 for 11 no days; 'bonhaze period from 24 July 1997 through 22 August for 20 no days; ${ }^{c} 12$ hr average for both daytime and nighttime; ${ }^{\mathrm{d}} \mathrm{D} / \mathrm{N}=$ (mean concentration during daytime)/(mean concentration during nighttime); ${ }^{\mathrm{e}}$ the ratio that has exhibited a significant diurnal variation at $P<0.05$.

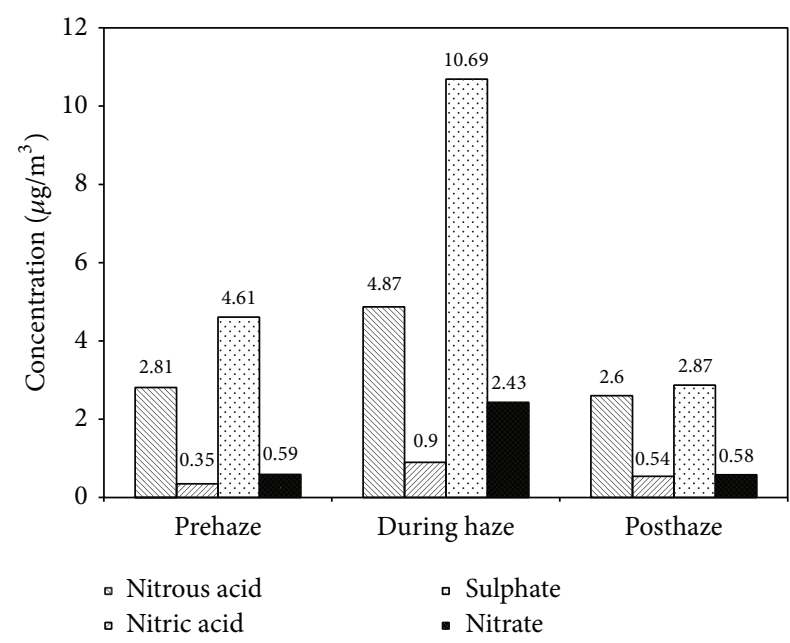

(a)

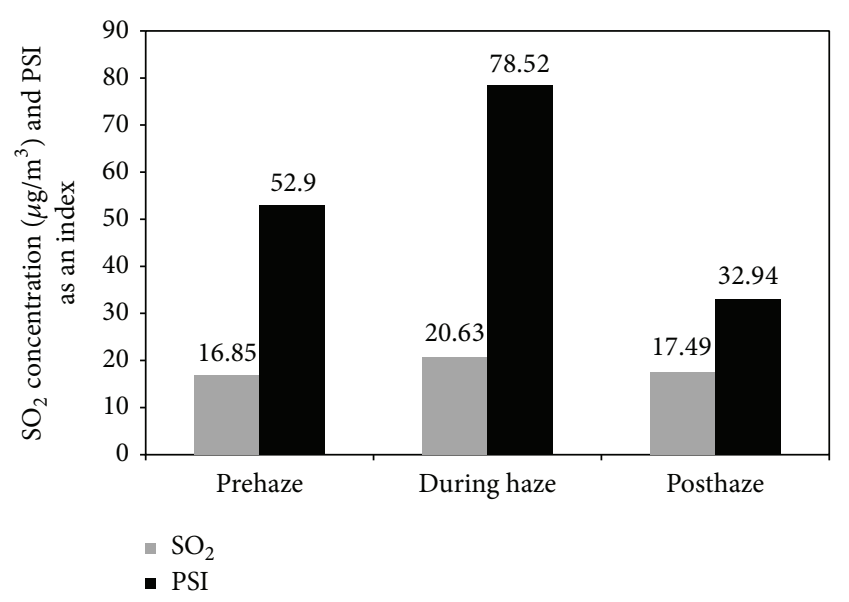

(b)

FIGURE 2: Daily mean concentrations of air pollutants and PSI during different time periods: (a) $\mathrm{HONO}, \mathrm{HNO}_{3}, \mathrm{SO}_{4}{ }^{2-}$, and $\mathrm{NO}_{3}{ }^{-}$ and (b) $\mathrm{SO}_{2}$ and PSI. of prehaze and posthaze episodes, respectively. So, it can be confirmed that except for $\mathrm{SO}_{2}$, all other parameters showed a significant variability between haze and nonhaze periods. Hence, the existing level of $\mathrm{SO}_{2}$ was most likely controlled by local emission levels.

The smoke haze that resulted from the forest fires from Indonesia had affected the concentrations of pollutants. Certain amounts of $\mathrm{HONO}, \mathrm{HNO}_{3}$, and $\mathrm{SO}_{2}$ and substantial amounts of particulates $\mathrm{NO}_{3}{ }^{-}$and $\mathrm{SO}_{4}{ }^{2-}$ may have been emitted directly from the forest fires. During the forest fires, $\mathrm{NO}$ and $\mathrm{NO}_{2}$, the precursors of $\mathrm{HONO}$ and $\mathrm{HNO}_{3}$ would be emitted from the burning of the $\mathrm{N}$ containing substances. Additionally, as airborne particulate is an important medium for all the atmospheric reactions, haze would therefore enhance these reactions. For example, the heterogeneous formation of $\mathrm{HONO}$ in the atmosphere could be enhanced during the smoke haze, as the haze particles could provide more reactive surfaces. Due to less intensive sunlight during the haze, the removal rate of HONO by the photolysis under sunlight radiation presumably decreased. During the smoke haze, some $\mathrm{HNO}_{3}$ may be produced from the dissociation of high concentrations of particulate $\mathrm{NO}_{3}{ }^{-}$which could be directly emitted from the forest fires or formed in the atmosphere from its precursors.

3.3. Daytime and Nighttime Observations. Table 2 presents the concentration of the measured species during daytime and nighttime. To assess the overall difference between daytime and nighttime levels of air pollutants and meteorological parameters, we performed a paired $t$-test with unequal variance for both haze and nonhaze periods. The results of the $t$-test showed that $\mathrm{HNO}_{3}$ during the haze period and $\mathrm{HONO}$ and $\mathrm{HNO}_{3}$ during the nonhaze period had showed significant diurnal variations at 95\% confidence level $(P<0.05)$. For meteorological parameters, temperature and wind speed during the haze period and temperature, relative humidity $(\mathrm{RH})$, wind speed, and wind direction showed significant 
diurnal variations at $95 \%$ confidence level $(P<0.05)$. Overall, $\mathrm{HNO}_{3}$ and $\mathrm{HONO}$ had much larger variations than $\mathrm{SO}_{2}$ and particulates $\mathrm{NO}_{3}{ }^{-}$and $\mathrm{SO}_{4}{ }^{2-}$, as they are photochemically reactive and therefore were affected to a great extent by the solar radiation.

Although $\mathrm{SO}_{2}$ did not show a significant daytime and nighttime variation, the nighttime concentration of $\mathrm{SO}_{2}$ was slightly higher than the value during the daytime (Table 2). The possible reasons for the observations could be due to the existence of relatively lower temperature and a lack of photochemical activities during the night that hindered the rate of transfer of $\mathrm{SO}_{2}$ from gas phase to particle phase $\left(\mathrm{SO}_{4}{ }^{2-}\right)$. In addition, wind speed at night was usually smaller than that during the daytime (Table 2) that resulted in lower dispersion of $\mathrm{SO}_{2}$ during nighttime.

During the nonhaze period, a significantly higher level of HONO concentration during nighttime (daytime/nighttime $(D / N)=0.6, P=0.018)$ can be explained by its heterogeneous formation and nighttime accumulation. HONO can be formed by a heterogeneous reaction of $\mathrm{NO}_{2}$ with $\mathrm{H}_{2} \mathrm{O}$, which can take place on wet surfaces, such as ground and aerosol particles $[45,46]$. The overall daytime and nighttime observations during nonhaze period for HONO were similar to the observations in other studies, such as in PRD, China [47], and Beijing, China [46].

In contrast to the observation of HONO during the nonhaze period, the differences between the nighttime and daytime values for HONO became less pronounced during the haze period. This is due to the decreased solar intensity in the daytime making the photolysis of HONO a much slower process. Earlier studies have shown that the diurnal change of HONO was less pronounced in the winter season due to the less intensity of the solar radiation [36].

$\mathrm{HNO}_{3}$ showed higher concentrations during the daytime and lower concentrations at nighttime for both haze and nonhaze periods, with $D / N=3.0$ and $P=0.014, D / N=2.0$ and $P=3.1 \times 10^{-6}$ for haze and nonhaze periods, respectively. The higher $\mathrm{HNO}_{3}$ during the daytime could be attributed to higher temperature, more solar radiation, and dry conditions, which favor formation of $\mathrm{HNO}_{3}$ through reactions between $\mathrm{NO}_{2}$ and $\mathrm{OH}$ radical (Hoek et al. 1996 [48]). In addition, due to semivolatile nature of $\mathrm{NH}_{4} \mathrm{NO}_{3}$ salt, the reverse reaction could be enhanced to produce more $\mathrm{HNO}_{3}$ due to higher temperature of the daytime [49]. This diurnal pattern was consistent and the observation of this study was similar to the observations reported in earlier studies $[45,46]$.

Although $\mathrm{SO}_{4}{ }^{2-}$ did not show statistically significant difference between daytime and nighttime observations, however the overall level of $\mathrm{SO}_{4}{ }^{2-}$ during the daytime was slightly higher than nighttime levels for both haze and nonhaze periods. The higher levels of $\mathrm{SO}_{4}{ }^{2-}$ during daytime could be explained through enhanced conversion of $\mathrm{NH}_{3}$ and $\mathrm{H}_{2} \mathrm{SO}_{4}$ into $\left(\mathrm{NH}_{4}\right)_{2} \mathrm{SO}_{4}$ in the presence of higher solar radiation that causes more levels of $\mathrm{OH}$ radicals [50].

In case of $\mathrm{NO}_{3}{ }^{-}$, we observed slightly higher levels during the daytime than the nighttime for both haze and nonhaze periods. The reason for such observations could be due to the humid conditions always prevailing in the atmosphere being in the tropical region. By comparing our results with the latest studies done in other regions of the world, our results were different (e.g., Sharma et al. [51] at Kanpur, India; $\mathrm{Hu}$ et al. [47] at Pearl River Delta, China; Poulain et al. [52] at Leipzig, Germany). These studies had observed that the formation of $\mathrm{NH}_{4} \mathrm{NO}_{3}$ in the ambient air was more favorable during the nighttime than the daytime due to higher $\mathrm{RH}$ in the night. To find the reason for such different observations in Singapore in this study, we had estimated the deliquescence relative humidity (DRH) of $\mathrm{NH}_{4} \mathrm{NO}_{3}$ during the daytime and nighttime by using the empirical relations between temperature and DRH from Stelson and Seinfeld [53]. The $24 \mathrm{hr}$ average $\mathrm{RH}$ during the measurement period was $81.2 \%$ and the DRH estimated was $63.2 \%$ for $\mathrm{NH}_{4} \mathrm{NO}_{3}$. These observations on DRH imply that existing humid conditions of the atmosphere in Singapore during the measurement period always favoured the formation of $\mathrm{NH}_{4} \mathrm{NO}_{3}$. In addition, more levels of $\mathrm{HNO}_{3}$ during the daytime had increased the extent for formation of $\mathrm{NO}_{3}^{-}$particles.

3.4. Diurnal Variations of Pollutants. Figure 3 shows the diurnal variations of $\mathrm{SO}_{2}, \mathrm{HONO}, \mathrm{HNO}_{3}, \mathrm{SO}_{4}{ }^{2-}$, and $\mathrm{NO}_{3}{ }^{-}$ during hazy and nonhazy days. The purpose of measurement for 2 hazy days and 2 nonhazy days was to assess the variations of these pollutants during different time intervals of the day and to get insights into the peaks of observations. The possible reasons for variations of these pollutants on the basis of day and night have been described in Section 3.2. The maximum of 4-hour concentrations of $\mathrm{SO}_{2}$ occurred from 7:00 PM to 11:00 PM during both hazy and nonhazy days. The reason for such high levels of $\mathrm{SO}_{2}$ can be explained through peak hours of the pollution activities and the local meteorological conditions causing less dispersion of the pollutant. The concentration of $\mathrm{SO}_{4}{ }^{2-}$ increased from the morning and peaked during 3:00 PM to 7:00 PM during both hazy and nonhazy days. The reason for the highest concentration of $\mathrm{SO}_{4}{ }^{2-}$ could be due to more solar radiation and temperature during 3:00 PM to 7:00 PM compared to other hours of the day that enhanced the production of $\mathrm{OH}$ radicals.

The maximum $\mathrm{HNO}_{3}$ concentration occurred from 11:00 AM to 3:00 PM during both hazy and nonhazy days. The reason for the highest $\mathrm{HNO}_{3}$ concentration can be attributed to a high temperature and low $\mathrm{RH}$ compared to other hours of the day that favour the formation of $\mathrm{HNO}_{3}$ through the reaction of $\mathrm{NO}_{2}$ and $\mathrm{OH}$ radical [48]. The peak of $\mathrm{NO}_{3}{ }^{-}$ that occurred from 7:00 AM to 3:00 AM during the haze and nonhaze periods could be attributed to peak hours of vehicular activities combined with lower $\mathrm{RH}$ that enhanced the formation $\mathrm{NO}_{3}{ }^{-}$particles.

The diurnal variations of pollutants revealed that the patterns were almost the same during hazy and nonhazy days for $\mathrm{SO}_{2}, \mathrm{HNO}_{3}, \mathrm{SO}_{4}{ }^{2-}$, and $\mathrm{NO}_{3}{ }^{-}$. However, the behaviour of HONO levels was different during haze and nonhaze periods. During nonhazy days, HONO showed clear and distinct peak from 11:00 PM to 3:00 AM and nighttime levels were more than daytime levels. In contrast, during hazy days, HONO did not show any clear and no pronounced difference between 


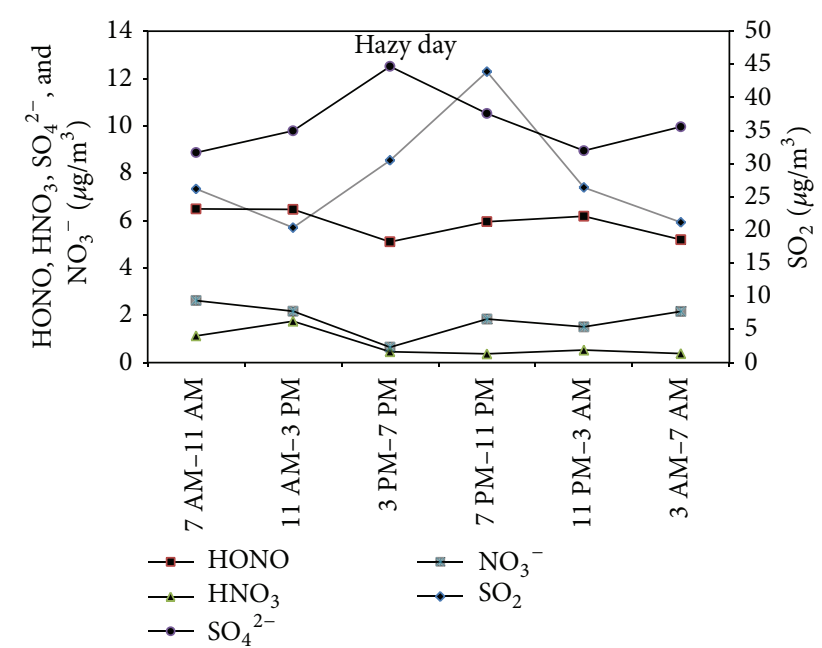

(a)

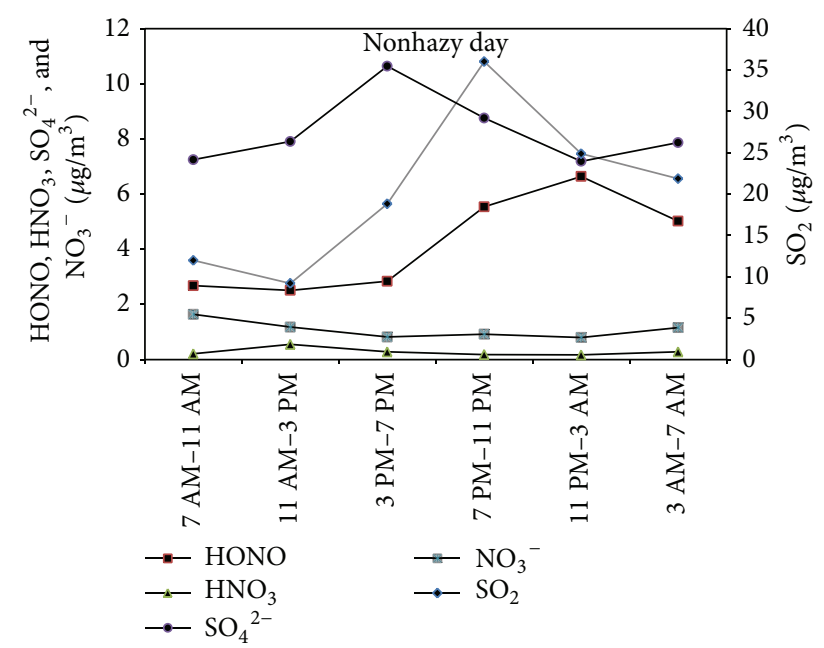

(b)

FIgURE 3: Diurnal variations of $\mathrm{SO}_{2}, \mathrm{HONO}, \mathrm{HNO}_{3}, \mathrm{SO}_{4}{ }^{2-}$, and $\mathrm{NO}_{3}{ }^{-}$during (a) hazy day and (b) nonhazy day.

daytime and nighttime levels was observed. The reason can be due to the fact that the smoke haze affected the solar radiation intensity to a great extent as explained in Section 3.2.

\subsection{Origin of Sources during Measurement Period. As} explained in Section 3.2, the pollution levels were high during the haze period compared to prehaze and posthaze periods. To identify the origin of sources responsible for additional pollution during the haze period, we constructed air mass trajectories reaching Singapore for different days using the HYSPLIT 4 model of the Air Resources Laboratory of NOAA [54]. We considered every measurement day to compute a $48 \mathrm{hr}$ (2 days) back trajectory at 14:00 local time with the option of $1000 \mathrm{~m}$ above the starting point, located at ground level and estimating new trajectory at every $6 \mathrm{hr}$. We used the computed archives trajectories with input options of meteorology and starting location as REANALYSIS (global, 1948Present). The model gave the outputs having coordinates of

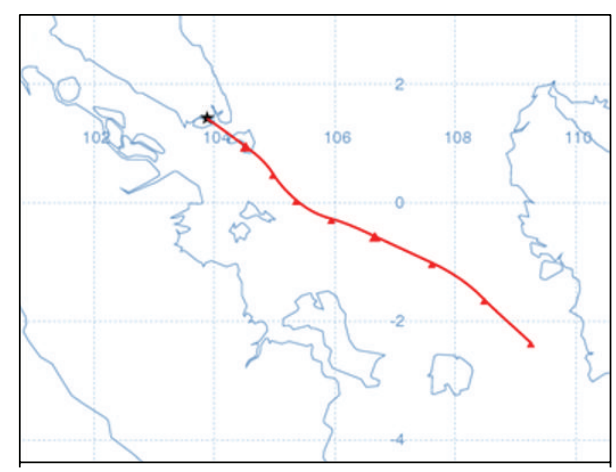

(a)

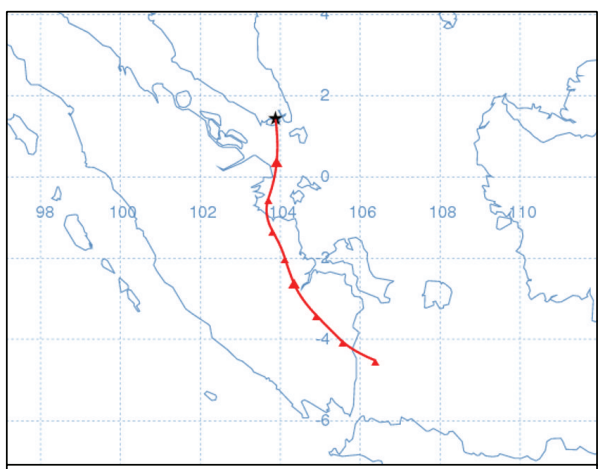

(b)

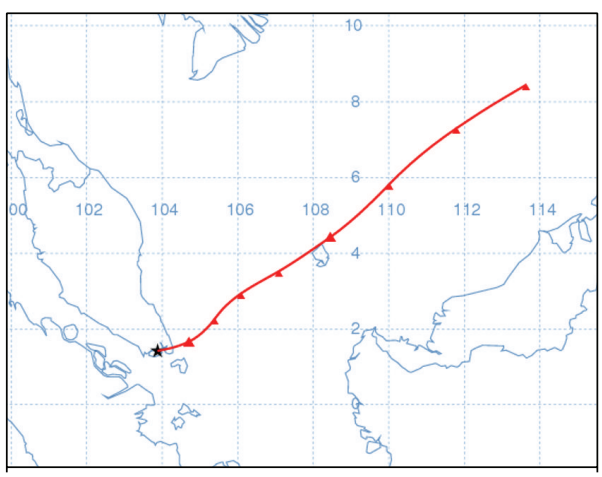

(c)

FIGURE 4: Representative days of backward air trajectories for three cases: (a) a prehazy day (14 June 1997); (b) a hazy day (29 August 1997); and (c) a posthazy day (05 December 1997).

the air parcel with respect to a set of latitudes and longitudes and having an outline map of the neighboring regions. We have classified all day-wise model outputs for three time periods (prehaze, haze, and posthaze). Figure 4 shows representatives of air mass trajectories for the measurement period.

Based on the frequency of occurrence of the air mass trajectories, the percentage of air masses from different directions was estimated for the entire measurement period. Figure 5 shows the distribution of 2-day backward air trajectories ending at Singapore during (a) prehaze period, (b) haze period, and (c) posthaze period. For the prehaze period, the air mass trajectories originated from south (S): 


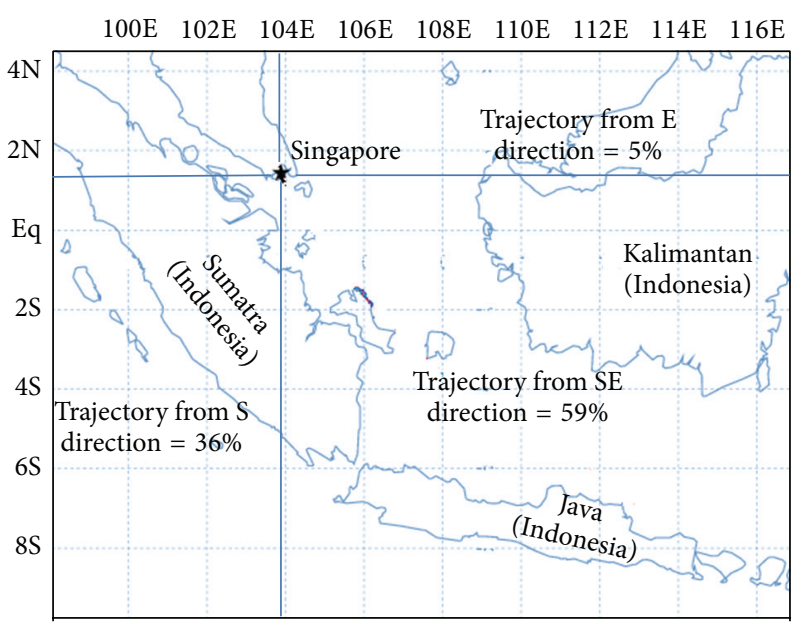

(a)

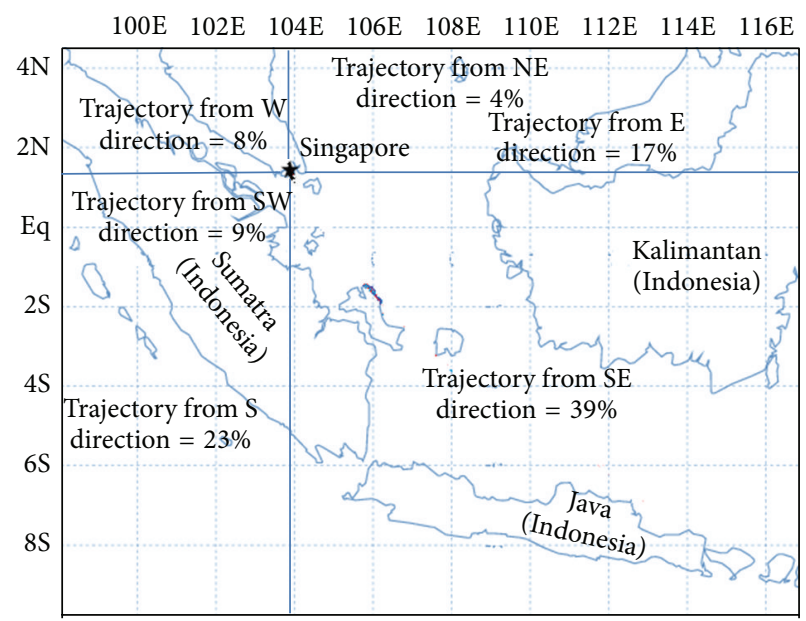

(b)

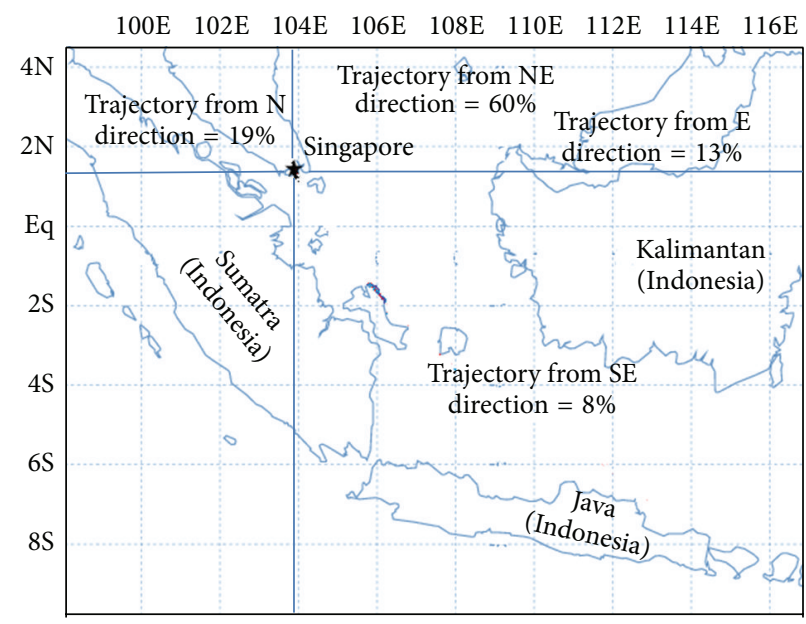

(c)

FIGURE 5: Distributions of 2-day back trajectories ending at Singapore during (a) prehaze, (b) haze, and (c) posthaze periods.

36\%; southeast (SE): $59 \%$; and east (E): $5 \%$. Similarly, the corresponding values for the haze period were S: $23 \%$; SE: $39 \%$; E: $17 \%$; northeast (NE): $4 \%$; west (W): $8 \%$; and southwest (SW): $9 \%$. For posthaze period, the values were SE: $8 \%$; E: 13\%; NE: $60 \%$; and north $(\mathrm{N}): 19 \%$. With these statistical data, the origin of air pollution sources during the haze episode was further examined.

Kadowaki [55] and Khoder [56] estimated the sulfur conversion ratio $\left(F_{s}\right)$ and the nitrogen conversion ratio $\left(F_{n}\right)$ with the following expressions:

$$
\text { Sulfur conversion ratio }\left(F_{s}\right)=\frac{\mathrm{SO}_{4}{ }^{2-}}{\mathrm{SO}_{2}+\mathrm{SO}_{4}{ }^{2-}}
$$

Nitrogen conversion ratio $\left(F_{n}\right)=\frac{\mathrm{PNO}_{3}{ }^{-}+\mathrm{GNO}_{3}{ }^{-}}{\mathrm{NO}_{2}+\mathrm{PNO}_{3}{ }^{-}+\mathrm{GNO}_{3}{ }^{-}}$

The terminologies in the above equations have been defined as follows: $\mathrm{SO}_{4}{ }^{2-}$ is the concentration in $\mu \mathrm{g} \mathrm{m}^{-3}$, $\mathrm{PNO}_{3}{ }^{-}$is the particulate nitrate concentration in $\mu \mathrm{g} \mathrm{m}^{-3}$,
$\mathrm{GNO}_{3}{ }^{-}$is the gaseous $\mathrm{NO}_{3}{ }^{-}$concentration, that is, $\mathrm{HNO}_{3}$ in $\mu \mathrm{g} \mathrm{m}^{-3}$, and $\mathrm{NO}_{2}$ is the gas phase concentration in $\mu \mathrm{g} \mathrm{m}^{-3}$.

Higher values of $F_{s}$ and $F_{n}$ indicate higher oxidation of gaseous species into SIA through secondary transformation processes. Wang et al. [57] had estimated these conversion ratios with the same approach for $F_{s}$ as illustrated by Kadowaki [55] and Khoder [56]. However, there was a slight modification in $F_{n}$ by removing the term $\mathrm{GNO}_{3}{ }^{-}$from (2). In this study, we have adapted (1) for estimation of $F_{s}$ and due to limitation of data of $\mathrm{NO}_{2}$ concentrations; $F_{n}$ was estimated with the following expression:

$$
\text { Nitrogen conversion ratio }\left(F_{n}\right)=\frac{\mathrm{PNO}_{3}^{-}}{\mathrm{PNO}_{3}{ }^{-}+\mathrm{GNO}_{3}{ }^{-}} \text {. }
$$

The purpose of estimating these parameters was to assess the origin of sources of these pollutants and to check whether the prevailing atmospheric conditions favor formation of secondary particulates $\mathrm{NO}_{3}{ }^{-}$and $\mathrm{SO}_{4}{ }^{2-}$. Table 3 presents certain parameters that were estimated during prehaze, haze, and posthaze periods. Both $F_{s}$ and $F_{n}$ were observed to 
be higher during the haze period than during prehaze and posthaze periods. It simply indicates that the hazy conditions were more favorable for formation of particulates $\mathrm{SO}_{4}{ }^{2-}$ and $\mathrm{NO}_{3}{ }^{-}$.

To verify this observation, the correlations of $F_{s}$ and $F_{n}$ with meteorology (temperature and $\mathrm{RH}$ ) were estimated. $F_{n}$ showed significant correlation with RH having $R^{2}=$ $0.82,0.91$, and 0.78 during prehaze, haze, and posthaze periods, respectively, with $P<0.001$. These consistent results suggested that the humid conditions favor the formation of particulate $\mathrm{NO}_{3}{ }^{-}$. The ratio of $\mathrm{HNO}_{3}$ to $\mathrm{NO}_{3}{ }^{-}$was lower during the haze period $(0.4 \pm 0.4)$ which supported the above observation; that is, haze conditions favored the formation of $\mathrm{NO}_{3}{ }^{-}$. Some earlier studies have also reported similar observations (e.g., $[56,58]$ ).

In the case of particulate $\mathrm{SO}_{4}{ }^{2-}, F_{s}$ showed significant correlations with temperature with $R^{2}=0.89$ and 0.81 during prehaze and posthaze periods, respectively, with $P<$ 0.001 . However, during the haze period, $F_{s}$ did not show any significant correlation with temperature with $R^{2}=0.37$ and with $P>0.05$. These inconsistent results suggested that hazy conditions did not favor the formation of particulate $\mathrm{SO}_{4}{ }^{2-}$. Several studies in the past (e.g., $[46,57,59])$ reported that the formation of particulate $\mathrm{SO}_{4}{ }^{2-}$ is more favorable during higher temperature and solar radiation. In Section 3.3, we explained that the diurnal variation of HONO did not follow usual trends during the haze period due to less intensity of solar radiation. Therefore, enhancement of the secondary formation of particulate $\mathrm{SO}_{4}{ }^{2-}$ during the haze period may not be the reason for the existing higher levels of particulate $\mathrm{SO}_{4}{ }^{2-}$. As a result, other sources such as $\mathrm{BB}$ might be responsible for particulate $\mathrm{SO}_{4}{ }^{2-}$.

From Table 3, it could be observed that the ratio of $\mathrm{SO}_{2}$ to $\mathrm{SO}_{4}{ }^{2-}$ during the haze period was about less than half of the values during prehaze and posthaze periods. These contradictory observations of particulate $\mathrm{SO}_{4}{ }^{2-}$ confirmed that hazy conditions cannot favor formation of $\mathrm{SO}_{4}{ }^{2-}$, especially below the haze layer. Hence, the sources of particulate $\mathrm{SO}_{4}{ }^{2-}$ could be local transformation and/or transported particulate $\mathrm{SO}_{4}{ }^{2-}$ from the $\mathrm{BB}$ region. In addition, particulate $\mathrm{SO}_{4}{ }^{2-}$ is a stable compound that can be transported to long distances after it is formed in the atmosphere [46].

$\mathrm{K}$ is a well-known indicator of the influence of biomassinduced smoke haze events on the ambient air quality in urban environments $[60,61]$. Although we did not measure the levels of particulate-bound $\mathrm{K}$ in the current study, we observed a huge spike in its concentration in rainwater along with those of $\mathrm{Cl}^{-}, \mathrm{NO}_{3}{ }^{-}, \mathrm{SO}_{4}{ }^{2-}, \mathrm{HCOO}^{-}, \mathrm{CH}_{3} \mathrm{COO}^{-}, \mathrm{Ca}^{2+}$, and $\mathrm{NH}_{4}{ }^{+}$during the smoke haze period [16]. In addition, large amounts of grey to black particles were noted in HDPE buckets used for rainwater collection and on Gelman AE filters following sample filtration during the biomass burning period, characterized by reduced atmospheric visibility. In our other biomass burning studies at the same sampling location as reported by See et al. [62] and Betha et al. [63], we observed the levels of particulate-bound $\mathrm{K}$ increased by about 3- to 10-fold during smoke haze events compared to nonhaze periods in 2001 and 2013, respectively [62, 63]. Thus, the relatively high concentrations of acidic gases and particulates $\mathrm{SO}_{4}{ }^{2-}$ and $\mathrm{NO}_{3}{ }^{-}$observed during the burning period can be attributed to a long residence time of air masses, leading to progressive gas-to-particle conversion of biomass burning emissions in Indonesia.

To assess the contribution of $\mathrm{BB}$ towards the existing pollution during haze periods in Singapore, we chose $\mathrm{SO}_{4}{ }^{2-}$ as the indicator of long-range transport of BB-impacted air masses. We assumed that the average ratio of $\mathrm{SO}_{2}$ into $\mathrm{SO}_{4}{ }^{2-}$ during prehaze and posthaze would remain constant during the haze period if the local atmospheric phenomenon were solely responsible for secondary particulate formation. Therefore, the difference in the concentration of $\mathrm{SO}_{4}{ }^{2-}$ between haze and nonhaze periods represents a rough estimate of the relative amount of $\mathrm{SO}_{4}{ }^{2-}$ derived from the long-range transport. As an illustrative example, the average ratio of $\mathrm{SO}_{2}$ to $\mathrm{SO}_{4}{ }^{2-}$ during prehaze and posthaze periods was 4.9 (Table 3 ). We assumed that this average ratio will be the same during the haze period. That means if the average concentration of $\mathrm{SO}_{2}$ in the haze period was $20.63 \mu \mathrm{g} \mathrm{m}^{-3}$ (Figure 2(b)), then $\mathrm{SO}_{4}{ }^{2-}$ concentration from local transformation sources would be $20.63 / 4.9=4.2 \mu \mathrm{g} \mathrm{m}^{-3}$ and the remaining concentration (Figure 2(a)), that is, $10.7-4.2=6.5 \mu \mathrm{g} \mathrm{m}^{-3}$, would be from the long-range transport mostly from the source of $\mathrm{BB}$ in Indonesia.

With the constant ratio of $\mathrm{SO}_{2}$ to $\mathrm{SO}_{4}{ }^{2-}$ (4.9), we estimated that long-transported $\mathrm{SO}_{4}{ }^{2-}$ component during haze periods was $6.5 \pm 3.6 \mu \mathrm{g} \mathrm{m}^{-3}$. In the next step, the percentage of particulate sulfate coming from different directions was assessed based on the results of backward trajectories during the haze period. It was estimated that the average amount of particulate $\mathrm{SO}_{4}{ }^{2-}$ came from SE, S, E, and SW directions as $2.5 \mu \mathrm{g} \mathrm{m}^{-3}, 1.5 \mu \mathrm{g} \mathrm{m}^{-3}, 1.1 \mu \mathrm{g} \mathrm{m}^{-3}$, and $0.6 \mu \mathrm{g} \mathrm{m}^{-3}$, respectively, during the hazy periods in Singapore. Overall, it can be concluded that up to $60 \%$ of particulate $\mathrm{SO}_{4}{ }^{2-}$ could have been transported from the $\mathrm{BB}$ occurring in Indonesia to Singapore.

\section{Conclusions}

A severe smoke haze episode was experienced in Singapore from August to October 1997 due to transboundary air pollution caused by uncontrolled forest and peat fires in Indonesia. An annular denuder system (ADS) was used for this study as an effective air sampler to collect acidic gases and fine particles in the ambient air from June 1997 to February 1998 to examine both temporal and diurnal variations of these pollutants during prehaze, haze, and posthaze episodes in the study area. The results revealed that the $24 \mathrm{hr}$ average concentrations of ambient $\mathrm{SO}_{2}, \mathrm{HONO}, \mathrm{HNO}_{3}, \mathrm{SO}_{4}{ }^{2-}$, and $\mathrm{NO}_{3}{ }^{-}$during the haze episodes had increased by a factor ranging from 1.2 to 4.2 compared to those during the prehaze and posthaze episodes. It was interestingly observed that $\mathrm{SO}_{2}$ did not proportionately increase during the haze period compared to $\mathrm{SO}_{4}{ }^{2-}$, which indicated that the transboundary particulate pollution originated from biomass burning in the 
TABLE 3: Indicators for formation of secondary formation during three episodes.

\begin{tabular}{lccc}
\hline Particulars of parameters & Prehaze period $($ mean \pm SD) & Haze period $($ mean \pm SD) & Posthaze period $(\mathrm{mean} \pm$ SD) \\
\hline Sulfur conversion ratio $\left(F_{s}\right)(\%)$ & $21.5 \pm 9.6$ & $34.1 \pm 13.7$ & $14.1 \pm 9.3$ \\
Nitrogen conversion ratio $\left(F_{n}\right)(\%)$ & $62.8 \pm 12.4$ & $72.9 \pm 15.8$ & $51.8 \pm 15.7$ \\
${\text { Ratio of } \mathrm{SO}_{2} \text { to } \mathrm{SO}_{4}{ }^{2-}}^{\text {Ratio of } \mathrm{HNO}_{3} \text { to } \mathrm{NO}_{3}{ }^{-}}$ & $3.6 \pm 2.4$ & $1.9 \pm 1.5$ & $6.1 \pm 4.6$ \\
\hline
\end{tabular}

SD: standard deviation.

neighboring regions. The study of atmospheric chemistry during the measurement period showed that the smoke haze period was more conducive for the formation of $\mathrm{NO}_{3}{ }^{-}$ particles in the local atmosphere. The diurnal trends of $\mathrm{SO}_{2}$, $\mathrm{HNO}_{3}, \mathrm{SO}_{4}{ }^{2-}$, and $\mathrm{NO}_{3}{ }^{-}$were the same during prehaze, haze, and posthaze periods. However, HONO showed different trends in haze and nonhaze periods. The daytime/nighttime concentration values of HONO were 0.6 and 1.0 during nonhaze and haze periods, respectively. The reason for such diurnal trends of HONO during the haze period could be due to the decreased solar intensity in the daytime making the photolysis of HONO a much slower process. From the results of backward air trajectory analysis, it can be concluded that the smoke haze episodes in Singapore that occurred due to transboundary air pollution caused by severe biomass burning in the islands of Indonesia had a major influence on the chemistry of the regional atmosphere in SEA and thus the regional air quality.

\section{Conflict of Interests}

The authors declare that there is no conflict of interests regarding the publication of this paper.

\section{Acknowledgments}

This research programme is funded by the National Research Foundation (NRF), Prime Minister's Office, Singapore, under its Campus for Research Excellence and Technological Enterprise (CREATE) programme. The authors are grateful to NRF for the financial support for preparation of the paper and article processing charges from Grant no. R-706-002-101-281.

\section{References}

[1] J. Fishman, K. Fakhruzzaman, B. Cros, and D. Nganga, "Identification of widespread pollution in the Southern Hemisphere deduced from satellite analyses," Science, vol. 252, no. 5013, pp. 1693-1696, 1991.

[2] M. G. Lawrence and J. Lelieveld, "Atmospheric pollutant outflow from southern Asia: a review," Atmospheric Chemistry and Physics, vol. 10, no. 22, pp. 11017-11096, 2010.

[3] R. Balasubramanian, S. Karthikeyan, J. Potter, O. Wurl, and C. Durville, "Chemical characterization of aerosols in the equatorial atmosphere over the Indian Ocean," Atmospheric Environment, vol. 78, pp. 268-276, 2013.

[4] R. J. Charlson and J. Heintzenberg, Aerosol Forcing of Climate, Wiley, Chichester, UK, 1995.
[5] S. Vedal, "Ambient particles and health: lines that divide," Journal of the Air and Waste Management Association, vol. 47, no. 5, pp. 551-581, 1997.

[6] IPCC: Intergovernmental Panel on Climate Change, The Physical Science Basis: Contribution of Working Group I to the Fourth Assessment Report of the Intergovernmental Panel on Climate Change, Edited by: S. Solomon, D. Qin, M. Manning et al., Cambridge University Press, Cambridge, UK, 2007.

[7] V. P. Aneja, W. H. Schlesinger, and J. W. Erisman, "Effects of agriculture upon the air quality and climate: research, policy, and regulations," Environmental Science and Technology, vol. 43, no. 12, pp. 4234-4240, 2009.

[8] S. N. Behera and M. Sharma, "Degradation of $\mathrm{SO}_{2}, \mathrm{NO}_{2}$ and $\mathrm{NH}_{3}$ leading to formation of secondary inorganic aerosols: an environmental chamber study," Atmospheric Environment, vol. 45, no. 24, pp. 4015-4024, 2011.

[9] N. Pérez, J. Pey, M. Cusack et al., "Variability of particle number, black carbon, and $\mathrm{PM}_{10}, \mathrm{PM}_{2.5}$, and $\mathrm{PM}_{1}$ levels and speciation: influence of road traffic emissions on urban air quality," Aerosol Science and Technology, vol. 44, no. 7, pp. 487-499, 2010.

[10] C. Reche, X. Querol, A. Alastuey et al., "New considerations for PM, black Carbon and particle number concentration for air quality monitoring across different European cities," Atmospheric Chemistry and Physics, vol. 11, no. 13, pp. 62076227, 2011.

[11] Y. Song, Y. Zhang, S. Xie et al., "Source apportionment of $\mathrm{PM}_{2.5}$ in Beijing by positive matrix factorization," Atmospheric Environment, vol. 40, no. 8, pp. 1526-1537, 2006.

[12] G. Lonati, M. Giugliano, and S. Ozgen, "Primary and secondary components of $\mathrm{PM}_{2.5}$ in Milan (Italy)," Environment International, vol. 34, no. 5, pp. 665-670, 2008.

[13] R. Derwent, C. Witham, A. Redington et al., "Particulate matter at a rural location in southern England during 2006: model sensitivities to precursor emissions," Atmospheric Environment, vol. 43, no. 3, pp. 689-696, 2009.

[14] G. Lammel and D. Perner, "The atmospheric aerosol as a source of nitrous acid in the polluted atmosphere," Journal of Aerosol Science, vol. 19, no. 7, pp. 1199-1202, 1988.

[15] R. M. Harrison and A. G. Allen, "Measurements of atmospheric $\mathrm{HNO}_{3}, \mathrm{HCl}$ and associated species on a small network in eastern England," Atmospheric Environment A: General Topics, vol. 24, no. 2, pp. 369-376, 1990.

[16] R. Balasubramanian, T. Victor, and R. Begum, "Impact of biomass burning on rainwater acidity and composition in Singapore," Journal of Geophysical Research D: Atmospheres, vol. 104, no. 21, pp. 26881-26890, 1999.

[17] R. Balasubramanian, W.-B. Qian, S. Decesari, M. C. Facchini, and S. Fuzzi, "Comprehensive characterization of $\mathrm{PM}_{2.5}$ aerosols in Singapore," Journal of Geophysical Research D: Atmospheres, vol. 108, no. 16, 2003.

[18] R. S. Kovats, "El Niño and human health," Bulletin of the World Health Organization, vol. 78, no. 9, pp. 1127-1135, 2000. 
[19] C. Y. Jim, “The forest fires in Indonesia 1997-98: possible causes and pervasive consequences," Geography, vol. 84, no. 3, pp. 251260, 1999.

[20] S. R. Aiken, "Runaway fires, smoke-haze pollution, and unnatural disasters in Indonesia," Geographical Review, vol. 94, no. 1, pp. 55-79, 2004.

[21] O. Kunii, S. Kanagawa, I. Yajima et al., “The 1997 haze disaster in Indonesia: Its air quality and health effects," Archives of Environmental Health, vol. 57, no. 1, pp. 16-22, 2002.

[22] M. Radojevic and H. Hassan, "Air quality in Brunei Darussalam during the 1998 haze episode," Atmospheric Environment, vol. 33, no. 22, pp. 3651-3658, 1999.

[23] T. R. Muraleedharan and M. Radojevic, "Personal particle exposure monitoring using nephelometry during haze in Brunei," Atmospheric Environment, vol. 34, no. 17, pp. 2733-2738, 2000.

[24] M. Radzi Bin Abas, D. R. Oros, and B. R. T. Simoneit, "Biomass burning as the main source of organic aerosol particulate matter in Malaysia during haze episodes," Chemosphere, vol. 55, no. 8, pp. 1089-1095, 2004.

[25] M. R. B. Abas, N. A. Rahman, N. Y. M. J. Omar et al., "Organic composition of aerosol particulate matter during a haze episode in Kuala Lumpur, Malaysia," Atmospheric Environment, vol. 38, no. 25, pp. 4223-4241, 2004.

[26] K. K. Chee, M. K. Wong, and H. K. Lee, "Microwave-assisted solvent extraction of air particulates for the determination of PAHs," Environmental Monitoring and Assessment, vol. 44, no. 1-3, pp. 391-403, 1997.

[27] I. Orlić, B. Wenlan, F. Watt, and S. M. Tang, "Air pollution in Singapore: its multielemental aspect as measured by nuclear analytical techniques," Environmental Monitoring and Assessment, vol. 44, no. 1-3, pp. 455-470, 1997.

[28] H. Du, L. Kong, T. Cheng et al., "Insights into summertime haze pollution events over Shanghai based on online water-soluble ionic composition of aerosols," Atmospheric Environment, vol. 45, no. 29, pp. 5131-5137, 2011.

[29] X. Y. Zhang, Y. Q. Wang, T. Niu et al., "Atmospheric aerosol compositions in China: spatial/temporal variability, chemical signature, regional haze distribution and comparisons with global aerosols," Atmospheric Chemistry and Physics, vol. 12, pp. 779-799, 2012.

[30] T. William, T. Ellestad, and B. Stevens, "Determination of reactive acidic and basic gases and strong acidity of fine particles (i $2.5 \mu \mathrm{m}$ ), EPA Report EPA/625/R-96/010a, 1997.

[31] M. J. Kennish, Practical Handbook of Marine Science, CRC Press, Boca Raton, Fla, USA, 1994.

[32] R. W. Shaw Jr., R. K. Stevens, and J. Bowermaster, "Measurements of atmospheric nitrate and nitric acid: the denuder difference experiment," Atmospheric Environment, vol. 16, no. 4, pp. 845-853, 1982.

[33] S. V. Hering, D. R. Lawson, I. Allegrini et al., "The nitric acid shootout: field comparison of measurement methods," Atmospheric Environment, vol. 22, no. 8, pp. 1519-1539, 1988.

[34] L. W. Richards, "Comments on the oxidation of $\mathrm{NO}_{2}$ to nitrate-day and night," Atmospheric Environment, vol. 17, no. 2, pp. 397-402, 1983.

[35] A. G. Russell, G. R. Cass, and J. H. Seinfeld, "On some aspects of nighttime atmospheric chemistry," Environmental Science and Technology, vol. 20, no. 11, pp. 1167-1172, 1986.

[36] M. Matsumoto and T. Okita, "Long term measurements of atmospheric gaseous and aerosol species using an annular denuder system in Nara, Japan," Atmospheric Environment, vol. 32, no. 8, pp. 1419-1425, 1998.
[37] N. T. Kim Oanh, N. Upadhyay, Y.-H. Zhuang et al., "Particulate air pollution in six Asian cities: spatial and temporal distributions, and associated sources," Atmospheric Environment, vol. 40, no. 18, pp. 3367-3380, 2006.

[38] A. Sjodin and M. Ferm, "Measurements of nitrous acid in an urban area," Atmospheric Environment A: General Topics, vol. 19, no. 6, pp. 985-992, 1985.

[39] I. Allegrini, F. De Santis, V. Di Palo et al., "Annular denuder method for sampling reactive gases and aerosols in the atmosphere," Science of the Total Environment, vol. 67, no. 1, pp. 1-16, 1987.

[40] R. Wetselaar, Ed., Nitrogen Cycling in South-East Asian Wet Monsoonal Ecosystems, Australian Academy of Science, Canberra, Australia, 1981.

[41] J. A. Logan, "Nitrogen oxides in the troposphere: global and regional budgets," Journal of Geophysical Research, vol. 88, no. 15, pp. 10785-10807, 1983.

[42] D. Perner, C. Kessler, and U. Platt, "HONO, $\mathrm{NO}_{2}$ and $\mathrm{NO}$ measurements in automobile engine exhaust by optical absorption," in Proceedings of the International Symposium on Monitoring Gaseous Pollutants by Tunable Diode Lasers, pp. 26-37, Freiburg, Germany, November 1986.

[43] D. P. Kaiser and Y. Qian, "Decreasing trends in sunshine duration over China for 1954-1998: indication of increased haze pollution?" Geophysical Research Letters, vol. 29, no. 21, pp. 38$1-38-4,2002$.

[44] S. N. Behera and M. Sharma, "Transformation of atmospheric ammonia and acid gases into components of $\mathrm{PM}_{2.5}$ : an environmental chamber study," Environmental Science and Pollution Research, vol. 19, no. 4, pp. 1187-1197, 2012.

[45] K. Acker, G. Spindler, and E. Brüggemann, "Nitrous and nitric acid measurements during the INTERCOMP2000 campaign in Melpitz," Atmospheric Environment, vol. 38, no. 38, pp. 64976505, 2004.

[46] Z. Wu, M. Hu, K. Shao, and J. Slanina, "Acidic gases, $\mathrm{NH}_{3}$ and secondary inorganic ions in $\mathrm{PM}_{10}$ during summertime in Beijing, China and their relation to air mass history," Chemosphere, vol. 76, no. 8, pp. 1028-1035, 2009.

[47] M. Hu, Z. Wu, J. Slanina, P. Lin, S. Liu, and L. Zeng, "Acidic gases, ammonia and water-soluble ions in $\mathrm{PM}_{2.5}$ at a coastal site in the Pearl River Delta, China," Atmospheric Environment, vol. 42, no. 25, pp. 6310-6320, 2008.

[48] G. Hoek, M. G. Mennen, G. A. Allen, P. Hofschreuder, and T. Van Der Meulen, "Concentrations of acidic air pollutants in The Netherlands," Atmospheric Environment, vol. 30, no. 18, pp. 3141-3150, 1996.

[49] B. J. Finlayson-Pitts and J. N. Pitts, Chemistry of the Upper and Lower Atmosphere, Academic Press, San Diego, Calif, USA, 1st edition, 2006.

[50] X. Ren, H. Wang, K. Shao, G. Miao, and X. Tang, "Determination and characteristics of $\mathrm{OH}$ radical in urban atmosphere in Beijing," Environmental Science, vol. 23, no. 4, pp. 24-27, 2002.

[51] M. Sharma, S. Kishore, S. N. Tripathi, and S. N. Behera, "Role of atmospheric ammonia in the formation of inorganic secondary particulate matter: a study at Kanpur, India," Journal of Atmospheric Chemistry, vol. 58, no. 1, pp. 1-17, 2007.

[52] L. Poulain, G. Spindler, W. Birmili, C. Plass-Dülmer, A. Wiedensohler, and H. Herrmann, "Seasonal and diurnal variations of particulate nitrate and organic matter at the IfT research station Melpitz," Atmospheric Chemistry and Physics, vol. 11, no. 24, pp. 12579-12599, 2011. 
[53] A. W. Stelson and J. H. Seinfeld, "Relative humidity and temperature dependence of the ammonium nitrate dissociation constant," Atmospheric Environment, vol. 16, no. 5, pp. 983-992, 1982.

[54] R. R. Draxler and G. D. Rolph, "HYSPLIT (HYbrid SingleParticle Lagrangian Integrated Trajectory) Model access via NOAA ARL READY," NOAA Air Resources Laboratory, Silver Spring, Md, USA, 2003, http://ready.arl.noaa.gov/HYS PLIT.php.

[55] S. Kadowaki, "On the nature of atmospheric oxidation processes of $\mathrm{SO}_{2}$ to sulfate and of $\mathrm{NO}_{2}$ to nitrate on the basis of diurnal variations of sulfate, nitrate, and other pollutants in an urban area," Environmental Science and Technology, vol. 20, no. 12, pp. 1249-1253, 1986.

[56] M. I. Khoder, "Atmospheric conversion of sulfur dioxide to particulate sulfate and nitrogen dioxide to particulate nitrate and gaseous nitric acid in an urban area," Chemosphere, vol. 49, no. 6, pp. 675-684, 2002.

[57] Y. Wang, G. Zhuang, A. Tang et al., "The ion chemistry and the source of $\mathrm{PM}_{2.5}$ aerosol in Beijing," Atmospheric Environment, vol. 39, no. 21, pp. 3771-3784, 2005.

[58] C.-M. Kang, H. S. Lee, B.-W. Kang, S.-K. Lee, and Y. Sunwoo, "Chemical characteristics of acidic gas pollutants and $\mathrm{PM}_{2.5}$ species during hazy episodes in Seoul, South Korea," Atmospheric Environment, vol. 38, no. 28, pp. 4749-4760, 2004.

[59] B. H. Baek, V. P. Aneja, and Q. Tong, "Chemical coupling between ammonia, acid gases, and fine particles," Environmental Pollution, vol. 129, no. 1, pp. 89-98, 2004.

[60] W. S. Siao, R. Balasubramanian, E. Rianawati, S. Karthikeyan, and D. G. Streets, "Characterization and source apportionment of particulate matter $\leq 2.5 \mu \mathrm{m}$ in Sumatra, Indonesia, during a recent peat fire episode," Environmental Science and Technology, vol. 41, no. 10, pp. 3488-3494, 2007.

[61] R. Betha, M. Pradani, P. Lestari, U. M. Joshi, J. S. Reid, and R. Balasubramanian, "Chemical speciation of trace metals emitted from Indonesian peat fires for health risk assessment," Atmospheric Research, vol. 122, pp. 571-578, 2013.

[62] S. W. See, R. Balasubramanian, and W. Wang, "A study of the physical, chemical, and optical properties of ambient aerosol particles in Southeast Asia during hazy and nonhazy days," Journal of Geophysical Research D: Atmospheres, vol. 111, no. 10, Article ID D10S08, 2006.

[63] R. Betha, S. N. Behera, and R. Balasubramanian, "2013 Southeast Asian smoke haze: fractionation of particulate-bound elements and associated health risk," Environmental Science \& Technology, vol. 48, no. 8, pp. 4327-4335, 2014. 

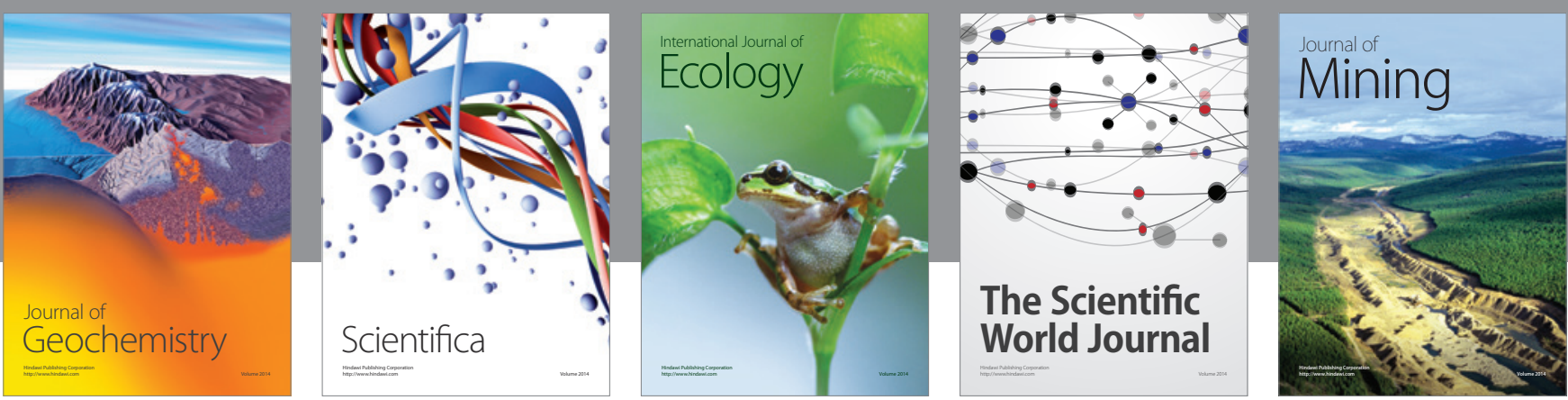

The Scientific World Journal
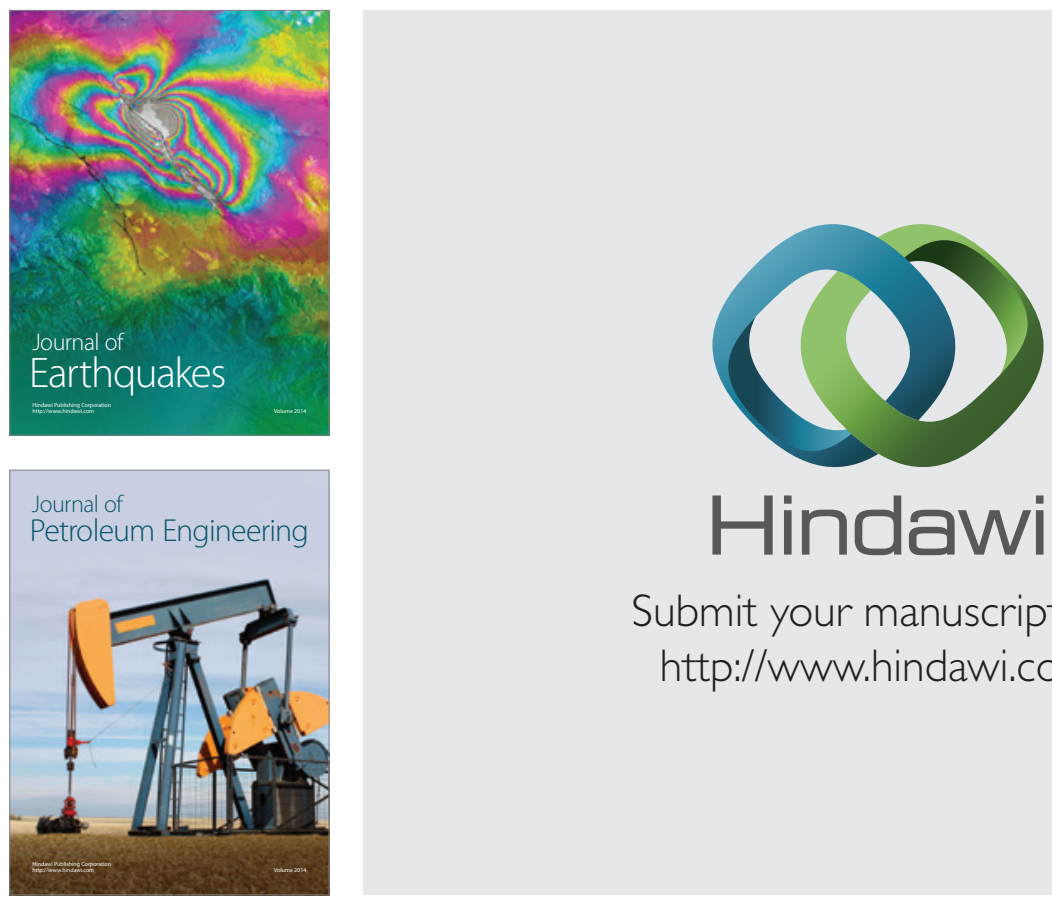

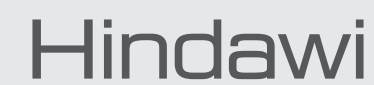

Submit your manuscripts at

http://www.hindawi.com
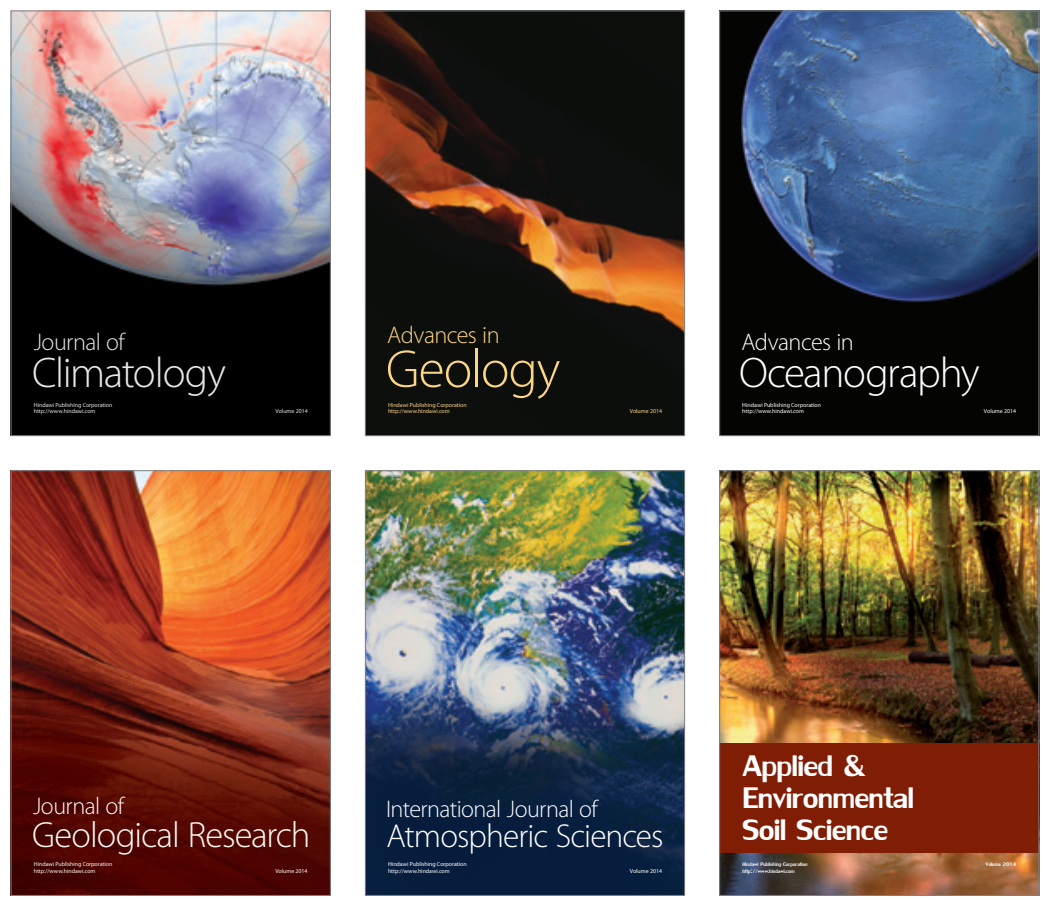
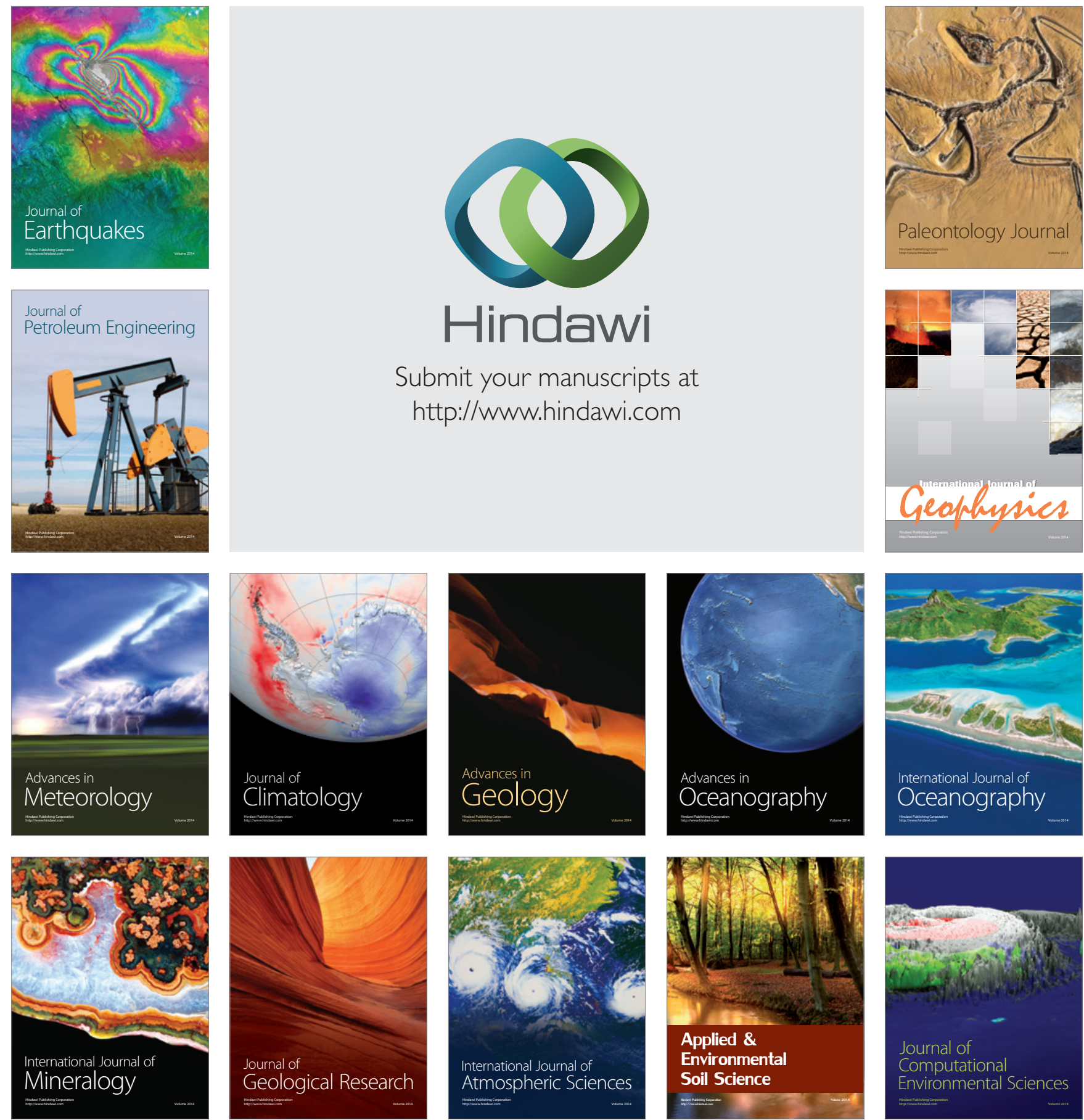